\title{
Tricuspid valve replacement with a mitral homograft in children with rheumatic tricuspid valvulopathy
}

\author{
Afksendiyos Kalangos, MD, PhD, FETCS ${ }^{a}$ \\ Jorge Sierra, MD \\ Maurice Beghetti, MD \\ Pedro Trigo-Trindade, $\mathrm{MD}^{\mathrm{c}}$ \\ Dominique Vala, $M D^{a}$ \\ Jan Christenson, MD, PhD, FETCS ${ }^{a}$
}

From the Clinic for Cardiovascular Surgery, ${ }^{\mathrm{a}}$ Unit for Pediatric Cardiology, ${ }^{\mathrm{b}}$ and Clinic for Cardiology, ${ }^{\mathrm{c}}$ University Hospital of Geneva, Geneva, Switzerland.

Received for publication Nov 4, 2003; revisions received Dec 17, 2003; accepted for publication Dec 31, 2003.

Address for reprints: Afksendiyos Kalangos, MD, PhD, Clinic for Cardiovascular Surgery, University Hospital of Geneva, 24, rue Micheli-du Crest, 1211 Geneva 17, Switzerland (E-mail: Afksendyios.Kalangos @ hcuge.ch).

J Thorac Cardiovasc Surg 2004;127:1682-7

$0022-5223 / \$ 30.00$

Copyright $\odot 2004$ by The American Association for Thoracic Surgery

doi:10.1016/j.jtcvs.2003.12.030
Objective: Tricuspid valve replacement in children is associated with a nonnegligible complication rate because of specific disadvantages of mechanical or biologic prostheses. The objective of this study was to examine the midterm clinical outcomes of tricuspid valve replacement with a mitral homograft in 8 children with unreparable rheumatic tricuspid valve involvement.

Methods: Between 1993 and 2003, tricuspid valve replacement with a mitral homograft was performed in 8 patients ( 2 male and 6 female patients; mean age, 14.2 years) with rheumatic tricuspid valve disease. All patients were in New York Heart Association class III or IV. In all patients with rheumatic valve disease, conservative operations had previously been performed on the tricuspid valve during concomitant left-sided surgical intervention. Mean follow-up was $56 \pm 12$ months and was complete.

Results: There were no operative or late deaths. All patients were alive at the most recent follow-up contact and were in New York Heart Association functional class I or II. None of the patients required homograft-related reoperation. At the most recent echocardiograhic examination, 6 patients had trivial residual tricuspid regurgitation, and 2 had mild tricuspid regurgitation. None of the patients had maximal transvalvular tricuspid gradients greater than $2 \mathrm{~mm} \mathrm{Hg}$ during their yearly follow-up visits.

Conclusion: On the basis of our midterm results, tricuspid valve replacement with a mitral homograft in children seems to be a valuable alternative surgical option.

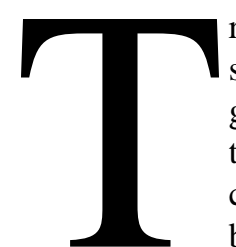

ricuspid valve (TV) dysfunction of rheumatic origin is usually associated with the involvement of the left-sided valves and can generally be corrected by using different annuloplasty or repair techniques if its severity requires intervention. However, in a few cases, TV lesions are not amenable to repair, and thus replacement becomes unavoidable. The choice of a valve substitute in the tricuspid position remains a mechanical or biologic prosthesis. Despite model changes and refinements, mechanical prostheses are predisposed to a high rate of thrombosis caused by lower pressures and slower flow rates in the right cardiac cavities. On the other hand, bioprostheses are threatened by their structural deterioration over time.

In view of these problems, we considered it of interest to replace the severely rheumatically involved TV with a mitral homograft. The purpose of this review is to examine the technical, as well as the clinical, aspects of this experience obtained in 8 patients and to report our midterm results. 


\section{Patients and Methods}

In our institution, over a 10-year period between September 1993 and September 2003, 227 children with mitral rheumatic valve disease, aortic rheumatic valve disease, or both underwent surgical intervention for the first time. At the time of the initial operation, 115 of the children underwent mitral valve (MV) repair, and 30 of them underwent MV replacement; a mechanical prosthesis was used in 27 of these latter patients, and a bioprosthesis was used in 3 of them. All these patients were operated on by the first author. Seventy-three of these 227 patients underwent mitral and aortic valve repair (cusp extension), and 9 of them underwent MV repair and concomitant aortic valve replacement with a cryopreserved aortic homograft. Of the total of 227 patients, 49 required concomitant intervention on their TV during the initial left-sided valvular surgery, indicating a prevalence of $21.6 \%$. Hemodynamically significant functional tricuspid insufficiency (TI) was present in $37(16.3 \%)$ patients. Before the initial operation, transthoracic echocardiography (TTE) was performed to assess the degree of functional TI, which was estimated as moderate to severe (grade III) in 31 patients and severe (grade IV) in 6 patients. Patients with grade III TI underwent concomitant De Vega annuloplasty, and those with severe functional TI (grade IV) underwent a concomitant Carpentier-Edwards tricuspid ring annuloplasty. In the second subset of 12 patients with organic TV lesions, 4 had predominantly severe stenotic lesions (maximal gradient, $>8 \mathrm{~mm}$ $\mathrm{Hg}$ ), and 8 of them had predominantly insufficient valves with grade III or IV insufficiency. The 4 patients with predominant tricuspid stenosis underwent concomitant commissurotomy associated with De Vega annuloplasty, and the 8 patients with predominant TI underwent a concomitant Carpentier-Edwards ring annuloplasty. In all these patients, the TI was reevaluated by means of TEE after being temporarily weaned from cardiopulmonary bypass $(\mathrm{CPB})$ after the left-sided valvular intervention. There was no discrepancy in terms of severity of TI between the preoperative TTE and peroperative transesophageal post-MV repair echocardiographic assessment. Tricuspid annuloplasty was then carried out on a beating heart during CPB.

From 1997 through 2003, 8 of these 12 children with organic TV lesions in whom conservative operations had been performed required a second intervention on their TV. The pathology encountered at the time of redo operation was predominantly severe recurrent TV stenosis (maximal gradient, $>8 \mathrm{~mm} \mathrm{Hg}$ ) in 5 patients and predominantly grade III or IV TI in the remaining 3 patients. One of these 5 patients with tricuspid stenosis had initially undergone a ring annuloplasty because of predominantly organic TI. However, at the time of the initial operation, the TV already presented a mild component of commissural fusion that evolved over time to become predominantly stenotic, probably induced by new episodes of recurrent rheumatic attacks.

Organic involvement of the TV was evident in all 12 patients on the preoperative TTE and subsequently confirmed visually during surgical intervention in 8 of them. The presence of commissural fusion, leaflet thickening or retraction, or both was considered as qualifying for organic involvement (Figure 1).

Eight patients undergoing TV replacement with a mitral homograft constitute our population in this clinical review. All these patients were again operated on by the first author. There were 6 female and 2 male patients, ranging in age from 12 to 16 years

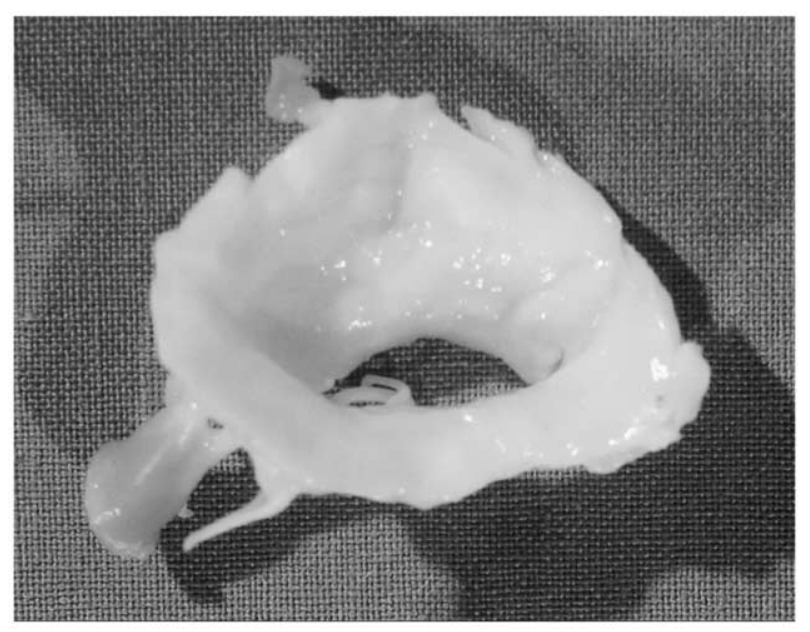

Figure 1. TV stenosis caused by organic involvement of rheumatic origin.

(mean, 14.2 years). As mentioned before, all patients had previously undergone open valve surgery. Two of them had previous aortic valve replacement with a cryopreserved aortic homograft associated with MV repair and tricuspid commissurotomy with De Vega annuloplasty. The remaining 6 patients had undergone previous MV repair. Concomitant tricuspid commissurotomy associated with De Vega annuloplasty had been performed in 2 of them, and a concomitant Carpentier-Edwards ring annuloplasty had been performed in 4 of them. In all 8 patients, the mean time period between initial valve surgery and TV replacement was $96 \pm 13$ months (range, 23-156 months). The tricuspid pathology encountered at the time of TV replacement was pure tricuspid stenosis in 5 patients and a combination of stenosis with predominant TI in the other 3 patients. The mean of maximal tricuspid transvalvular gradients measured by means of TTE in the 5 patients with pure tricuspid stenosis was $12 \mathrm{~mm} \mathrm{Hg}$ (range, 8-16 mm $\mathrm{Hg}$ ). Five patients were in New York Heart Association (NYHA) functional class IV, and 3 patients were in NYHA class III. Ascites was present in 2 patients, hepatomegaly in 4 patients, and peripheral limb edema in 5 patients. No concomitant cardiac procedure was necessary in these cases during the redo operations. TTE evaluation of the other cardiac valves before redo operations showed good functioning of the aortic homograft, with trivial diastolic leak in 2 patients and residual mitral leaks in 8 patients (mild in 6 patients and moderate in 2 patients). The mean transvalvular mitral gradient in these 8 patients was $4 \pm 2 \mathrm{~mm} \mathrm{Hg}$ (range, $3-8 \mathrm{~mm} \mathrm{Hg}$ ).

All patients underwent median resternotomy after cannulation of the femoral vein and artery. Adhesions were liberated, and the superior vena cava was selectively cannulated with a curved venous cannula. TV replacement was performed in all cases on a beating heart through a right atriotomy after snaring both venae cavae. The TV was completely removed by incising the valve circumferentially. Some of the septal leaflet was preserved to avoid atrioventricular block by allowing for the suture of the homograft's posterior muscular rim to this remnant of the septal leaflet. The chordae tendinae were removed from the tips of the papillary muscles. The size of the homograft had been previously deter- 
mined by means of measurements made on echocardiography, with the most important dimension being the anteroposterior diameter of the tricuspid orifice during diastole. A mitral homograft was chosen so that the length of its anterior leaflet was approximately the same as the anteroposterior diameter of the tricuspid orifice. On the basis of our experience, neither the length of the MV chordae tendinae nor the configuration of the papillary muscles is important in the choice of the appropriate mitral homograft dimensions. In preparation for subsequent ring annuloplasty, horizontal mattress sutures of 2-0 braided polyester were placed around the perimeter of the tricuspid annulus, except for the anteroseptal commissure area and half of the septal annulus close to this commissure. After thawing, the cryopreserved homograft was trimmed by cutting away the excess myocardium from the annulus of the mitral homograft. The anterior papillary muscle was shortened, leaving only 8 to $10 \mathrm{~mm}$ of tissue below its chordal attachments. This shortening provides some ability to set the chordal length and hence avoids a deeper incision into the interventricular septum. The posterior papillary muscle, on the other hand, was kept intact to have enough tissue to place it through the small ventriculotomy on the diaphragmatic surface of the right ventricle parallel to the posterior descending branch of the coronary artery (Figure 2, A). The most appropriate site for implantation of the posterior papillary muscle was chosen by measuring the length of the posterior primary mitral chordae and applying the same length to the distance from the tricuspid annulus to the eventual site of implantation on the diaphragmatic surface of the right ventricle. The length of the anterior chordae tendinae was then measured, and the same length was applied to the distance from the septal annulus to the anteroseptal commissure on the interventricular septum to determine the eventual implantation site of the anterior papillary muscle. An oblique incision was carefully performed at this site by detaching a muscular layer of $2 \mathrm{~cm}$ in depth from the interventricular septum. The anterior papillary muscle was then inserted into this opening and secured with a running 3-0 polypropylene suture passed through the detached layer and the interventricular septum (Figure 2,B). The rationale for the implantation into the interventricular septum rather than the right ventricular anterior wall was to avoid any interference with the right ventricular outflow tract flow. The mitral homograft was attached to the tricuspid annulus with continuous stitches of 4-0 polypropylene after aligning the posterior leaflet between the anteroseptal commissure and the middle of the posterior tricuspid annulus (Figure 2, $C$ ). The replaced TV was then supported with a Carpentier-Edwards tricuspid ring (Figure 2,D). The size of this ring was chosen according to the sizer corresponding to the surface of the anterior leaflet of the mitral homograft. The size of the ring was $32 \mathrm{~mm}$ in 6 patients and $34 \mathrm{~mm}$ in the other 2 patients. Valve competence after repair was then tested by means of infusion of saline under pressure into the right ventricle after temporarily clamping the ascending aorta together with the pulmonary trunk. No patients had either prophylactic anticoagulant or antiplatelet regimens after surgical intervention.

\section{Results}

All patients survived the operation and are alive at the time of this report. No mitral homograft-related complications were encountered in these 8 patients. All patients were in sinus rhythm postoperatively, except for 2 patients who had atrial flutter-fibrillation that responded to amiodarone. Mitral homograft function was assessed by means of 2-dimensional echocardiography and Doppler color flow velocity both preoperatively and postoperatively. Postoperative mean length of hospital stay was $9 \pm 2$ days (range, 7-12 days). The mean follow-up period was $56 \pm 8$ months (range, 5-80 months). All patients had regular TTE studies before hospital discharge and at the first, third, and sixth postoperative months. Four patients who were referred to our institution from African countries by a welfare foundation returned to their countries of origin 6 months after their operations and were then followed by means of questionnaires sent to their referring cardiologists, who evaluate the homograft function at regular yearly TTE studies. At the sixth postoperative month, echocardiographic examination showed that 2 of these 4 patients had trivial residual TI, and 2 of them had mild residual TI. The maximal transvalvular gradients across the homograft were $2 \mathrm{~mm} \mathrm{Hg}$ in 3 patients and $1.4 \mathrm{~mm} \mathrm{Hg}$ in 1 patient. Up to the most recent follow-up study, referring cardiologists did not find any significant changes in terms of these echocardiographic parameters. The other 4 patients had regular yearly TTE examinations. In all 4 patients, echocardiographic studies showed satisfactory functioning of the mitral homograft over time (Figure 3 ). In these same 4 patients, the last echocardiographic study showed that the residual leak was trivial, and the maximal transvalvular gradient was estimated at $2 \mathrm{~mm} \mathrm{Hg}$ in 3 patients and at $1.2 \mathrm{~mm} \mathrm{Hg}$ in 1 patient. Moreover, there was no evidence of calcification or progressive leaflet restriction on repeated TTE studies over the follow-up period. One of these children was referred to our institution 3 years after the replacement of her TV with a mitral homograft because of progression of the degree of residual mitral insufficiency of her native valve from moderate to severe. In this patient the MV had been replaced with a porcine bioprosthesis. At the time of reintervention, the mitral homograft in the tricuspid position was explored through a right atriotomy. The mobility of both leaflets was perfect, the papillary muscles were completely incorporated into the myocardium, and the prosthetic ring was entirely covered by fibrosis. Saline injection into the right ventricle showed good coaptation between both leaflets and no residual leak (Figure 4). Observation of papillary muscle healing at the time of reintervention for MV surgery showed secure approximation of the graft to the recipient. The donor papillary muscles appeared to have been totally replaced by scar tissue, leaving the homograft chordae tendineae attached to the tips of the papillary muscles. At the last follow-up study, 6 patients were in NYHA class I, and 2 were in NYHA class II. 

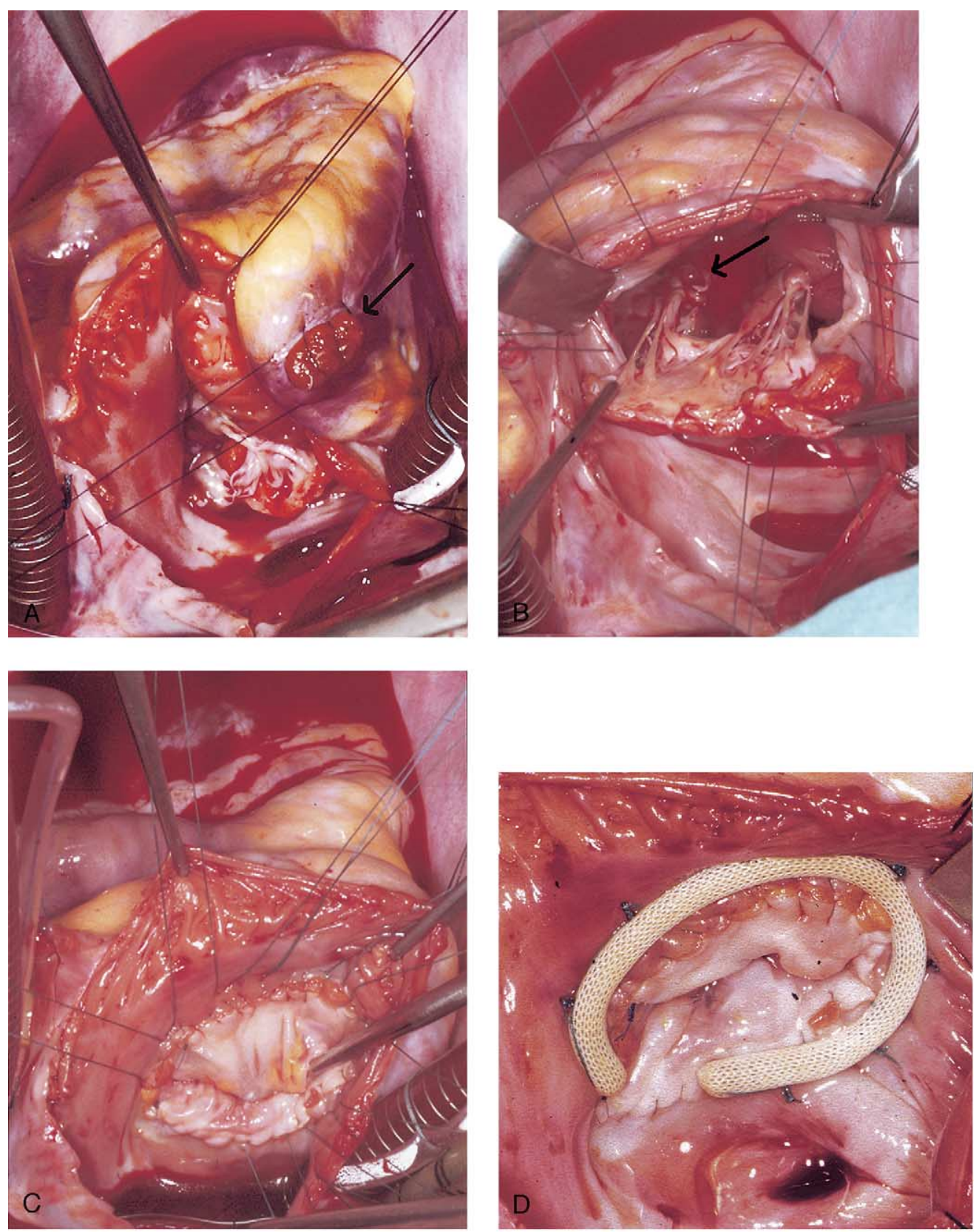

Figure 2. A, Implantation of the posterior papillary muscle into the small right ventriculotomy (arrow) parallel to the posterior descending branch of the coronary artery. B, Implantation of the anterior papillary muscle into the trench created in the interventricular septum (arrow). C, Attachment of the mitral homograft to the tricuspid annulus. D, Carpentier-Edwards prosthetic ring.

\section{Discussion}

Tricuspid annuloplasty is an excellent surgical technique and yields satisfactory results in the correction of functional TI. Although organic TV disease can be initially repaired in 95\% of cases, subsequent TV replacement becomes mandatory in some cases because of the progression of rheumatic valvular disease or the ignorance of its severity during the initial repair combined with left-sided valve surgery. ${ }^{1}$
Since 1993, when Pomar and Mestres ${ }^{2}$ published their 16-month experience of total TV replacement with a mitral homograft in 3 patients with right-sided infective endocarditis and demonstrated the technical feasibility and reliability of the operation, homograft replacement of the TV became an appealing alternative to biologic or mechanical prostheses. Many reports then described TV replacement with a mitral homograft with satisfactory midterm results 

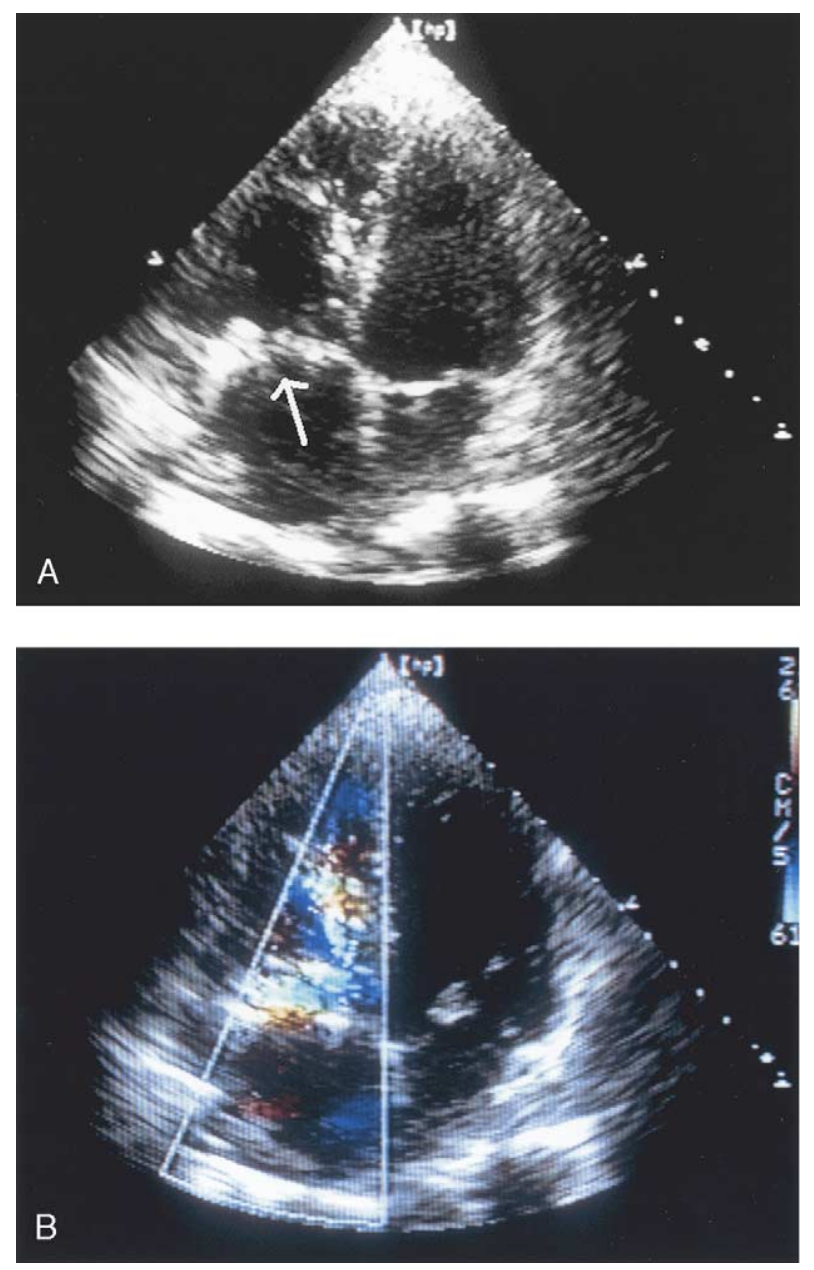

Figure 3. Echocardiographic control at the 50th postoperative month showing good coaptation surface between leaflets (arrow) in systole (A) with no residual leak (B).

and complete clinical cure of right-sided infective endocarditis. $^{3-5}$

When a decision is made to replace the TV, the choice between mechanical and biologic prostheses remains controversial. Both types of valvular substitutes have specific advantages and disadvantages, especially in the pediatric population, for which an ideal substitute has yet to be developed. Some authors have reported that bioprostheses in the tricuspid position perform well up to 10 years after implantation but can show some structural deterioration, this finding being especially pronounced in children..$^{6-9}$ Kawahira and colleagues ${ }^{10}$ reported a stenosis rate of $57 \%$ caused by calcification of the implanted bioprostheses in children at between 4 and 9 years after initial replacement. The lower pressures and flow rates in the right cardiac cavities predispose mechanical prostheses to a high incidence of valve thrombosis despite improvements in the new bileaflet design. ${ }^{10-12}$ Although the outlook for these patients

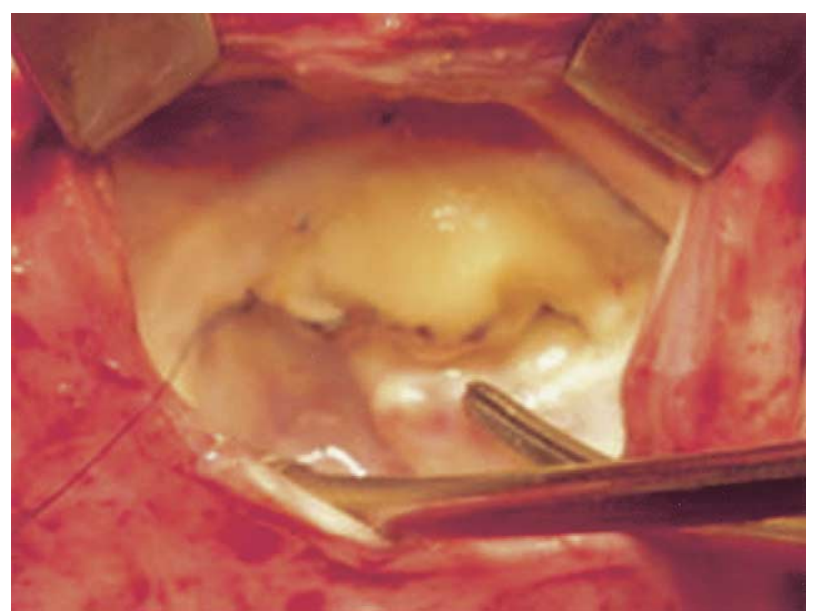

Figure 4. Mitral homograft in the tricuspid position 62 months after surgical intervention showing good coaptation between both leaflets after saline injection into the right ventricle.

is excellent, the recommended level of anticoagulation for a mechanical prosthesis (international normalized ratio of 3.5-4.5) in the tricuspid position carries the risk of hemorrhage. The risk and inconvenience of anticoagulation becomes even greater in children and young female patients during childbearing years. Moreover, anticoagulant medication is undesirable in children who live in some developing countries where no adequate facilities for periodic assessments of international normalized ratio are available. For these above-mentioned reasons, we consider TV replacement with a mitral homograft a valuable alternative surgical option.

TV replacement with a mitral homograft is a technically challenging operation, the most crucial point being the positioning of the mitral homograft in the right ventricle. Locating the proper points of implantation of the mitral papillary muscles and attaching them should be properly done, although on the right side, the conditions affecting the security of fixation appear to be somewhat different, possibly resulting from reduced stress on the chordae in a lowpressure cavity. The length of the homograft's anterior leaflet is the key factor determining the choice of the correct homograft size. This length should be longer than the anteroposterior diameter of the tricuspid annulus in diastole, as measured on TTE, to ensure a satisfactory coaptation line between both leaflets during systole, which is further reinforced by an annuloplasty ring. Each of these 3 steps of the operation, which can be carried out on a beating heart during CPB by bicaval cannulation, standardizes the procedure in terms of the reproducibility and predictability of midterm results. Thanks to the use of a systematic criterion for the choice of valve size and the adjustment of chordal length, the degree of immediate residual TI, which varied from trivial to mild in our series, remained stable during the follow-up period. This fact also proves that the residual 
regurgitation present just after implantation is directly related to the surgical procedure and not to the dysfunction of the graft.

It is speculated that differences between the structural change of implanted bioprostheses in the mitral and tricuspid positions might mainly be due to the effect of mechanical stress on the cusps. We believe this hypothesis is also valid for mitral homografts in the tricuspid position, as demonstrated with an aortic homograft valve functioning for 28 years in the tricuspid position. ${ }^{13}$ Despite this unique case, further experience is needed to assess the long-term performances of mitral homografts in the tricuspid position.

In summary, the mitral homograft in the tricuspid position is a promising valvular substitute for the pediatric population in whom anticoagulant medication is not otherwise indicated or is undesirable. Long-term follow-up is obviously needed to ascertain clinical results and to compare hemodynamic performance with that of biologic prostheses.

\section{References}

1. Duran C. Tricuspid valve surgery revisited. J Card Surg. 1994;9: 242-7.

2. Pomar JL, Mestres CA. Tricuspid valve replacement using a mitral homograft. Surgical technique and initial results. J Heart Valve Dis. 1993;2:125-8.
3. Pomar JL, Mestres CA, Pare JC, Miro JM. Management of persistent tricuspid endocarditis with transplantation of cryopreserved mitral homografts. J Thorac Cardiovasc Surg. 1994;107:1460-3.

4. Miyagishima RT, Brumwell ML, Jamieson E, Munt BI. Tricuspid valve replacement using a cryopreserved mitral homograft. Surgical technique and initial results. J Heart Valve Dis. 2000;9:805-9.

5. Mestres CA, Miro JM, Pare JC, Pomar JL. Six-year experience with cryopreserved mitral homografts in the treatment of tricuspid valve endocarditis in HIV-infected drug addicts. J Heart Valve Dis. 1999; 8:575-7.

6. McGrath LB, Chen C, Bailey BM, Fernandez J, Laub GW, Adkins MS. Early and late phase events follow in bioprosthetic tricuspid valve replacement. J Card Surg. 1992;7:245-9.

7. Kawachi Y, Tominaga R, Hisahara M, Nakashima A, Yasui H, Tokunaga K. Excellent durability of the Hancock porcine bioprosthesis in the tricuspid position: a sixteen-year follow-up. $J$ Thorac Cardiovasc Surg. 1992;104:1561-6.

8. Dunn JM. Porcine valve durability in children. Ann Thorac Surg. 1981;32:357-68

9. Pasque M, Williams WG, Coles JG, et al. Tricuspid valve replacement in children. Ann Thorac Surg. 1987;44:164-8.

10. Kawashira Y, Yagihara T, Uemura H, Yoshizumi K, Yoshikawa Y, Kitamura S. Replacement of the tricuspid valve in children with congenital cardiac malformations. J Heart Valve Dis. 2000;9:636-40.

11. Mestres CA, Igual A, Murtra M. The Björk-Shiley tilting disc valve in the tricuspid position: 10 year experience. Scand J Thorac Cardiovasc Surg. 1983;17:197-9.

12. Singh AK, Feng WC, Sanofsky SJ. Long-term results of St. Jude Medical valve in the tricuspid position. Ann Thorac Surg. 1992;54: 538-40.

13. Kawauchi M, Saigusa M, Furuse A, Takamato S. Aortic homograft valve functioning for twenty-eight years in the tricuspid position. J Thorac Cardiovasc Surg. 1999;118:384. 